\title{
Adhesion molecule expression in primary sclerosing cholangitis and primary biliary cirrhosis
}

\author{
S Bloom, K Fleming, R Chapman
}

\begin{abstract}
There are conflicting reports regarding intercellular adhesion molecule-1 (ICAM1) expression in primary sclerosing cholangitis (PSC) and primary biliary cirrhosis (PBC). Expression of adhesion molecules ICAM-1, lymphocyte adhesion molecule-1 (LFA-1), vascular cell adhesion molecule (VCAM), and E-selectin was examined together with HLA-DR in 16 liver biopsy specimens showing PSC and 12 specimens showing PBC. These were compared with biopsy specimens showing large duct obstruction $(n=7)$, chronic active hepatitis $(n=4)$, alcoholic liver disease $(n=4)$, and normal liver histological results $(n=5)$. ICAM-1 was detected on biliary epithelium in five of seven PSC specimens of histological stage 3 or 4, but not in nine early PSC specimens or in specimens from disease controls. In PBC, ICAM-1 was positive on three of 12 cases, two stage 2, and one stage 3. Nine of 16 PSC specimens (three of nine early, six of seven late disease) and six of 10 PBC specimens (three early, three late disease) were positive for HLADR. LFA-1 stained infiltrating inflammatory cells in PSC, PBC, and disease controls. In conclusion, ICAM-1 expression on biliary epithelium in PSC occurs mainly in late stage disease and therefore may be secondary to previous events inducing inflammation rather than of primary pathogenic importance. ICAM-1 expression in PBC is less common and not clearly associated with a particular disorder. Previous reports of ICAM-1 prevalence may have been biased towards end stage, pre-transplantation biopsy specimens.

(Gut 1995; 36: 604-609)
\end{abstract}

Department of Gastroenterology

$S$ Bloom

R Chapman

and University of Oxford Nuffield

Department of

Pathology and

Bacteriology

K Fleming

John Radcliffe Hospital, Oxford

Correspondence to: Dr S L Bloom,

Gastroenterology Research

Unit, University Departmen

of Medicine, Liverpool

L69 3BX.

Accepted for publication 28 July 1994
Keywords: adhesion molecules, primary sclerosing cholangitis, primary biliary cirrhosis.

Primary sclerosing cholangitis (PSC) and primary biliary cirrhosis (PBC) are both chronic cholestatic liver diseases with progressive destructive inflammatory fibrosis of intrahepatic bile ducts, especially the septal and interlobular bile ducts. Although certain histological features can be used to distinguish the two diseases, such as the presence of a granulomatous cholangitis lesion in PBC and a fibrous obliterative cholangitis lesion in PSC, in many cases distinguishing histological abnormalities are not found in liver biopsy specimens from these patients. ${ }^{1}$ While the aetiology of both diseases is unknown, there is evidence to suggest that immunological mechanisms may be important. There is an association of PSC with HLA-B8-DR3$\mathrm{DRw} 52 \mathrm{a},{ }^{23}$ a haplotype that is associated with other organ specific autoimmune diseases. Abnormalities in lymphocyte subsets exist in peripheral blood and liver in PSC, ${ }^{45}$ and PBC. ${ }^{6}$ In PSC there is an increased percentage of suppressor/cytotoxic $\mathrm{T}$ lymphocytes that become activated on exposure to autologous major histocompatability complex antigens. ${ }^{7}$ In both PSC and PBC increased expression of class II antigens on biliary epithelium has been shown. ${ }^{89}$ Infiltrating $\mathrm{T}$ cells have been shown to be closely associated with areas of bile duct destruction in both diseases. ${ }^{510}$ Further evidence of immune mediation has come from the finding of circulating non-organ specific and organ specific antibodies, ${ }^{1} 1112$ and the association of PSC in $70 \%$ of cases with ulcerative colitis, a putative autoimmune disease. ${ }^{12}$ Despite these studies the pathogenic mechanisms of bile damage are not clear.

Cell adhesion molecules (CAMs) are known to be important in a range of cellular interactions, ${ }^{13}$ especially antigen dependent cellular cytotoxicity and leucocyte-endothelial interactions. Recognition by the TCR/CD3 complex on $T$ cells of an antigen presented in association with major histocompatability complex molecules transiently stimulates adhesiveness through a conformational change in lymphocyte function associated molecule 1 (LFA-1), permitting regulation of adhesion and detachment over a timescale of minutes. ${ }^{14}$ LFA-1 on the surface of leucocytes can bind to the ligands intercellular adhesion molecule-1 (ICAM-1), ${ }^{15}$ ICAM-2, ${ }^{16}$ and ICAM-3. ${ }^{17}$ While expression of ICAM-2 and ICAM-3 is largely constitutive, expression of ICAM-1 can be induced by proinflammatory cytokines such as interferon gamma and tumour necrosis factor alpha, ${ }^{18}$ which suggests it may have a role in regulating the inflammatory response. Increased expression of MHC class II molecules on biliary epithelium in PSC and PBC has been reported by others, ${ }^{19} 20$ which suggests that antigen presentation by these cells may participate in $T$ cell activation. Adhesion molecules have also been implicated in mediating leucocyte adherence to endothelium before diapedesis and emigration into tissue spaces. Members of the selectin family such as E-selectin (formerly ELAM-1) expressed on vascular endothelium have been shown to mediate the early phase of leucocyte adhesion by recognition of a variety of sialylated and fucosylated ligands on the leucocyte cell surface. ${ }^{2122}$ This is followed by a 
second wave of adhesion events involving immunoglobulin superfamily members such as ICAM-1 and vascular cell adhesion molecule 1 (VCAM-1) on vascular endothelium, binding to integrins LFA-1 and VLA-4 respectively on the leucocyte cell surface. This 'second wave' is crucial to leucocyte sticking and diapedesis across endothelium into surrounding tissues. ${ }^{23}$ ${ }^{24}$ This process of migration of leucocytes into tissues is crucial to immune surveillance.

Recent studies have examined the expression of adhesion molecules in liver inflammation, ${ }^{25}$ and there have been conflicting reports of the extent and significance of ICAM-1 expressed in livers of patients with PSC and PBC, ${ }^{26} 27$ which may result, in part, from differences in severity of disease in different studies. The aim of this study was to discover if adhesion molecules are expressed on biliary epithelium at a disease stage consistent with a role in pathogenesis of cell mediated damage.

\section{Methods}

\section{PATIENTS}

Forty eight liver biopsy samples were collected from the following groups of patients: PSC (16 specimens from a total of 15 patients), PBC $(n=12)$, normal histological tests $(n=4)$, alcoholic liver disease $(n=4)$, chronic active hepatitis $(n=4$; one resulting from hepatitis $C$, three autoimmune), and large duct obstruction $(n=7)$. Diagnosis of PSC was established by persistently abnormal liver enzyme activities, liver histological examination, and endoscopic retrograde cholangiopancreatography changes. ${ }^{28} 29$ Diagnosis of PBC was by accepted clinical and pathological criteria. ${ }^{1} 30$ Specimens were classified into those showing early disease (stage 1 or 2 ) and those showing late disease (stage 3 or 4) according to the criteria of Ludwig et al. ${ }^{31} 32$ The patients with chronic active hepatitis were taking prednisolone. None of the others were taking any immunosuppressive drugs. No patient was taking ursodeoxycholic acid. One patient with PSC had two liver biopsies, three years apart.

\section{STUDY DESIGN}

Liver biopsy specimens were snap frozen and stored in liquid nitrogen. Immunohistochemistry was carried out using both three stage immunoalkaline phosphatase and three stage immunoperoxidase techniques. Frozen sections were fixed in acetone for 10 minutes and air dried for 15 minutes, then stained for 30 minutes with primary monoclonal antibodies. Optimal dilutions were established using preliminary titration studies (data not shown); pure antibodies were used at $1 / 1000$, diluted in phosphate buffered saline $/ 5 \%$ fetal calf serum $/ 0 \cdot 02 \%$ sodium azide, and supernatants were used neat or $1 / 10$. Mouse monoclonal antibodies used included $18 \mathrm{C} 11$ and $15 \cdot 2$ (anti-ICAM-1, British Biotechnology, Oxford), MHM-24 (anti-LFA-1), IF11 (anti
E-selectin), 4B2 (anti-VCAM), and Tal $14 \cdot 1$ (anti HLA-DR, a gift from Dr D Mason, John Radcliffe Hospital, Oxford). The mouse monoclonal antibody DG99 (anti-pneumocystis) was used as a negative control, as well as staining without the presence of primary antibody. After washing, slides were processed for either APAAP or a three stage immunoperoxidase technique. For APAAP, sections were incubated with rabbit antimouse immunoglobulin, (DAKO, High Wycombe, UK) at a dilution of $1 / 40$ for 30 minutes, then with a complex of alkaline phosphatase coupled to mouse antialkaline phosphatase immunoglobulin for 30 minutes. After further 10 minute incubations with rabbit antimouse $\mathrm{Ig}$ and alkaline phosphatase conjugate, sections were developed using napthol-AS-biphosphate as substrate and new fuchsin as chromogen. For immunoperoxidase staining, sections were incubated with peroxidase labelled rabbit antimouse immunoglobulin at 1/50 dilution followed by peroxidase labelled swine antirabbit, again at 1/50 dilution, and then developed with 3,3'diaminobenzidine tetrahydrochloride. Sections were scored by a histopathologist (KF) unaware of the identity of sections or antibodies. Staining was scored as either positive or negative; doubtful cases were reviewed by two of the authors (KF, SB) and a consensus reached.

As in similar studies, ${ }^{27}$ bile ducts were analysed in three categories according to size: proliferating bile ductules (the smallest duct branches with a generally inconspicuous lumen, usually confined to marginal zones in portal areas), interlobular ducts (small ducts of diameter 20-100 $\mu \mathrm{m}$ ), and larger ducts of greater than $100 \mu \mathrm{m}$ diameter, usually septal or trabecular ducts. Other structures assessed were hepatocytes, endothelium, sinusoidal lining cells, infiltrating inflammatory cells, and the degree of duct damage.

This study conformed to local ethical guidelines.

\section{Results}

Both APAAP and immunoperoxidases techniques showed similar sensitivity, but APAAP gave rather higher background staining than immunoperoxidase.

\section{BILE DUCTS AND DUCTULES}

Most biopsy specimens contained more than three portal tracts. In general, all bile ducts or ductules in any specimen were either positive or negative. A few specimens showed focal positivity, with roughly equal numbers of positive and negative staining ducts or ductules. Biliary epithelium was negative for anti-VCAM and E-selectin in all cases. ICAM1 was not detected on duct and ductular epithelium in normal controls or in patients with chronic active hepatitis, large duct obstruction, or alcoholic liver disease. ICAM-1 staining was seen in the bile ductules and smaller ducts of five of 16 PSC specimens (Table I). These patients were all histological 
TABLE I Immunohistochemical data on patients with PSC

\begin{tabular}{|c|c|c|c|c|c|}
\hline Patient & Stage & $\begin{array}{l}\text { Associated } \\
I B D\end{array}$ & $\begin{array}{l}\text { ICAM ducts } \\
>100 \mu \mathrm{m}\end{array}$ & $\begin{array}{l}\text { ICAM } \\
\text { ducts/ductules }\end{array}$ & $\begin{array}{l}\text { HLA-DR } \\
\text { ducts/ductules }\end{array}$ \\
\hline \multicolumn{6}{|c|}{ Early disease } \\
\hline $1^{\star}$ & 2 & $\mathrm{CD}$ & Focal +ve & $-\mathrm{ve}$ & tve \\
\hline 2 & 2 & UC & Focal +ve & $-\mathrm{ve}$ & $+\mathrm{ve}$ \\
\hline 3 & $\overline{1}$ & UC & ND & $-\mathrm{ve}$ & $-\mathrm{ve}$ \\
\hline 4 & i & $C D$ & $\mathrm{Neg}$ & - ve & $-\mathrm{ve}$ \\
\hline 5 & 2 & UC & ND & $-\mathrm{ve}$ & $-\mathrm{ve}$ \\
\hline 6 & 2 & UC & ND & - ve & -ve \\
\hline 7 & $\overrightarrow{1}$ & $\mathrm{CD}$ & ND & - ve & - ve \\
\hline 8 & 1 & $\mathrm{CD}$ & - ve & - ve & +ve \\
\hline 9 & 1 & UC & - ve & -ve & -ve \\
\hline \multicolumn{6}{|c|}{ Late disease } \\
\hline 10 & 3 & UC & - ve & $+\mathrm{ve}$ & +ve duct \\
\hline $11^{\star}$ & 3 & $\mathrm{CD}$ & tve & $+\mathrm{ve}$ & +ve \\
\hline 12 & 3 & UC & $+v e$ & +ve & +ve \\
\hline 13 & 3 & None & Focal +ve & - ve & tve \\
\hline 14 & 3 & UC & +ve & tve & tve \\
\hline 15 & 3 & UC & $-\mathrm{ve}$ & $-\mathrm{ve}$ & $-\mathrm{ve}$ \\
\hline 16 & 3 & UC & ND & $-\mathrm{ve}$ & $-v e$ \\
\hline
\end{tabular}

${ }^{\star}$ Biopsy specimens taken from the same patient three years apart. ND=Not detected. $+\mathrm{ve}=$ positive, $-\mathrm{ve}=$ negative. $\mathrm{CD}=$ Crohn's disease, $\mathrm{UC}=$ ulcerative colitis.

stage 3, and all expressed HLA-DR on bile ducts and ductules. Specimens from two patients with early PSC (patients 1 and 2, Table I) and one patient with late PSC (Table I, no 13), showed focal positivity for ICAM-1 on septal bile ducts but were negative on proliferating ductules: these patients bile ducts stained positive for HLA-DR. One patient had two liver biopsy specimens examined, the first at diagnosis (Table $I$, no 1 ) and the second some three years later (Table I, no 11). During this time his biopsy appearances had gone from stage 2 to stage 3 and he developed ICAM positivity on bile ductules (Fig $1 \mathrm{~A}$ and $\mathrm{B}$ ).

Two of seven early PBC specimens showed staining of proliferating ductules and medium sized interlobular ducts with anti-ICAM (Table II, nos 18 and 19, and Fig 2) although larger sized ducts (that is, septal/trabecular) were not seen in four cases. One of five late PBC specimens showed positive staining of

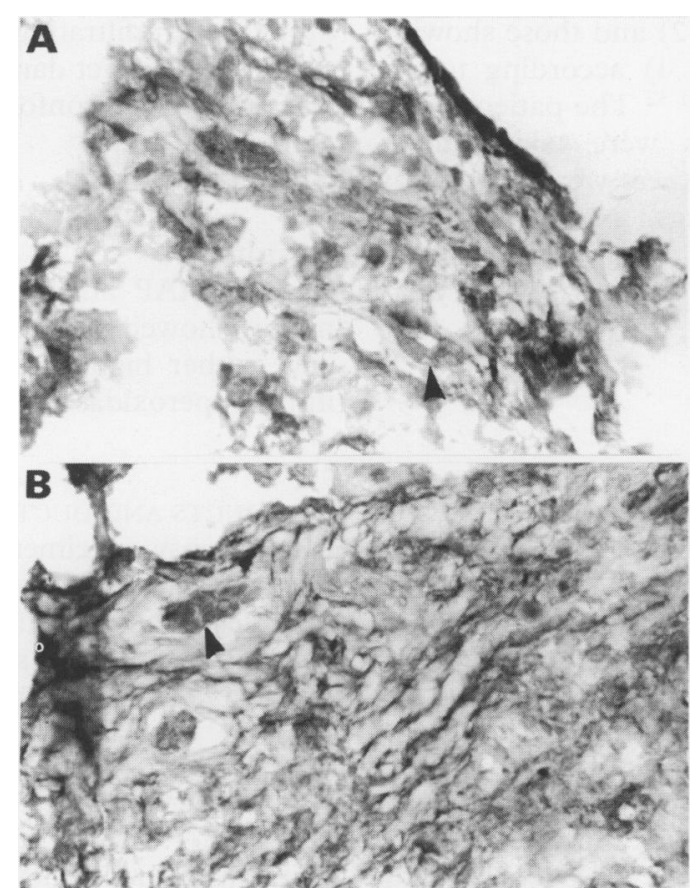

Figure $1(A)$ and $(B)$ : Section of stage 2 PSC stained with anti-ICAM (4a) showing negative proliferating bile ductules and interlobular bile ducts. Three years later disease has progressed to stage 3 and small bile ducts (arrowed) have become positive (patients 1 and 11, Table I).

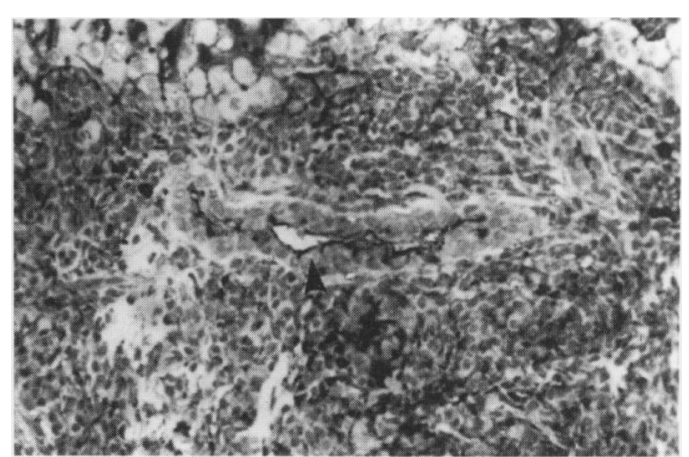

Figure 2: ICAM-1 antibody staining proliferating ductule and interlobular bile duct (arrowed) in PBC patient 18, Table II).

proliferating ductules but not interlobular ducts with anti-ICAM (Table II, no 28).

\section{HLA-DR EXPRESSION}

HLA-DR was absent from biliary epithelium of normal controls and patients with alcoholic liver disease, but was present on the bile ducts of six of seven cases of large duct obstruction (see Table 3). HLA-DR was expressed on biliary epithelium in a case of chronic active hepatitis resulting from hepatitis $C$ and was expressed weakly and focally in one of three cases of 'autoimmune' chronic active hepatitis.

Bile ductular epithelium was positive for MHC class II expression in three of nine specimens of early PSC (Table I, nos $1,2,8$ ): in all three, ductules were negative for ICAM. In advanced PSC, six of seven specimens showed ductal expression of HLA-DR and also of ICAM-1 (Table I and Fig 3).

In PBC, bile ducts and ductules were positive for HLA-DR in three of seven early specimens examined and three of five late specimens. Two of these were also positive for ICAM (Table II, nos 18, 28).

PARENCHYMAL, ENDOTHELIAL, INFLAMMATORY, AND SINUSOIDAL CELL STAINING

In normal liver, hepatocytes were negative to ICAM-1. There was membranous staining of hepatocytes of varying intensity with ICAM-1 antibodies (Fig 4) in PSC, PBC, and disease control biopsy specimens. In general, intensity of staining correlated with degree of inflammatory infiltrate. No other antibodies stained

TABLE II Immunohistochemical data on PBC patients

\begin{tabular}{|c|c|c|c|c|}
\hline Patient & Stage & $\begin{array}{l}\text { ICAM ducts } \\
>100 \mu \mathrm{m}\end{array}$ & $\begin{array}{l}\text { ICAM } \\
\text { ducts/ductules }\end{array}$ & $\begin{array}{l}\text { HLA-DR } \\
\text { ducts/ductules }\end{array}$ \\
\hline \multicolumn{5}{|c|}{ Early disease } \\
\hline 17 & 2 & ND & $-\mathrm{ve}$ & - ve \\
\hline 18 & 2 & + ve & +ve & + ve \\
\hline 19 & 2 & $+\mathrm{ve}$ & $+\mathrm{ve}$ & - ve \\
\hline 20 & 2 & -ve & $-v e$ & - ve \\
\hline 21 & 1 & ND & $-\mathrm{ve}$ & $+\mathrm{ve}$ \\
\hline 22 & 2 & ND & - ve & +ve \\
\hline 23 & 1 & ND & - ve & - ve \\
\hline \multicolumn{5}{|c|}{ Late disease } \\
\hline 24 & 3 & ND & $-\mathrm{ve}$ & $-\mathrm{ve}$ \\
\hline 25 & 3 & - ve & $-v e$ & +ve \\
\hline 26 & 4 & $-\mathrm{ve}$ & - ve & $+\mathrm{ve}$ \\
\hline 27 & 3 & -ve & -ve & $-v e$ \\
\hline 28 & 4 & - ve & +ve & $+\mathrm{ve}$ \\
\hline
\end{tabular}

Abbreviations as in Table I. 
TABLE III Summary of ICAM-1 and HLA-DR staining

\begin{tabular}{|c|c|c|c|c|}
\hline & \multirow[b]{2}{*}{ No } & \multicolumn{2}{|l|}{$I C A M+v e$} & \multirow{2}{*}{$\begin{array}{l}\text { HLA-DR +ve } \\
\text { ducts/ductules }\end{array}$} \\
\hline & & Ducts & Ductules & \\
\hline PSC stage $1 / 2$ & 9 & $2 / 9$ & $0 / 9$ & 3 \\
\hline PSC stage $3 / 4$ & 7 & $4 / 7$ & $5 / 7$ & 4 \\
\hline PBC stage $1 / 2$ & 7 & $2 / 3(4 \mathrm{ND})$ & $2 / 7$ & $3 / 7$ \\
\hline PBC stage $3 / 4$ & 5 & $0 / 4$ (1 ND) & $1 / 5$ & $3 / 5$ \\
\hline LDO & 7 & 0 & 1 & 6 \\
\hline CAH & 4 & 0 & 0 & 1 \\
\hline ALD & 4 & 0 & 0 & 0 \\
\hline Normal & 5 & 0 & 0 & 0 \\
\hline
\end{tabular}

$\mathrm{LDO}=$ large duct obstruction, $\mathrm{CAH}=$ chronic active hepatitis, $\mathrm{ALD}=$ alcoholic liver disease.

hepatocytes. There was weak endothelial staining in portal tracts and hepatocytes lobules with anti-VCAM and anti-E-selectin in many biopsy specimens with no detectable difference in staining between inflamed and control specimens. Antibodies to ICAM-1 stained vascular endothelium in all specimens. Infiltrating inflammatory cells were also uniformly positive for HLA-DR. Dual staining with LFA-1 and ICAM-1 to look for LFA-1 positive lymphocytes adhering to ICAM-1 positive ducts was not performed and comparing serial sections was technically unsatisfactory. Generally, however, infiltrating inflammatory cells, where present, expressed LFA-1 in all sections (Fig 5). All sections showed expression of ICAM-1, E-selectin, and VCAM on sinusoidal cells. We found very similar staining of sinusoidal cells with anti-HLA-DR agreeing with other studies. ${ }^{8}$ This sinusoidal cell staining was not perceptibly increased in either PSC or disease controls compared with normal specimens.

\section{Discussion}

Cell adhesion molecules play a key part in facilitating intercellular events between immune effector and target cells. In particular the interaction of the leucocyte surface molecule LFA-1 with its ligands ICAM 1, 2, and 3 has received considerable interest. ${ }^{15-17}$ After antigen specific recognition by the TCR/CD3 complex, intracellular signals are generated, which transiently convert LFA-1 to a high avidity state, and provides a mechanism for regulating cell adhesion and de-adhesion in an antigen specific manner within a time course of minutes. ${ }^{33}$ This greatly facilitates the delivery of the 'lethal hit' by the cytotoxic T cell.

Expression of adhesion molecules on liver parenchymal cells, sinusoidal and vascular endothelium has been reported to be increased

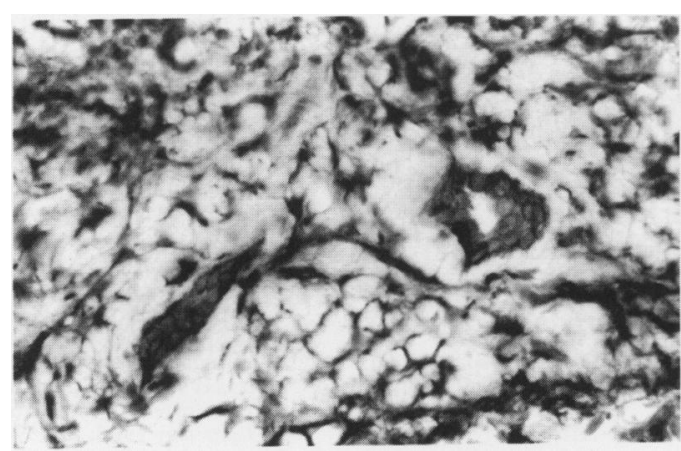

Figure 3: HLA-DR expressed on biliary epithelium in stage 3 PSC (patient 2, Table I).

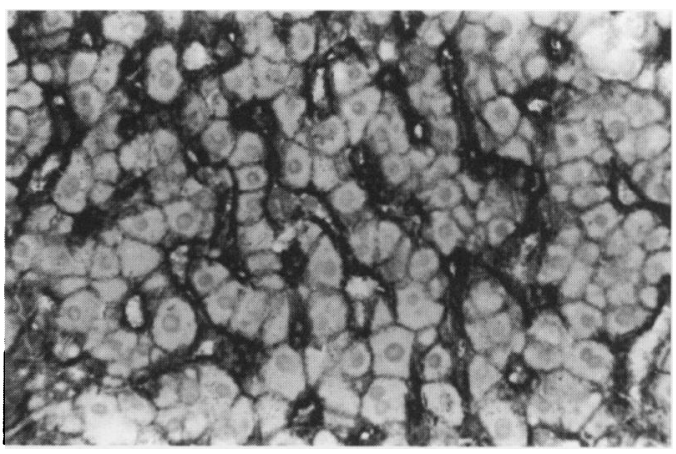

Figure 4: Membranous staining of hepatocytes by anti-ICAM-1 in PSC (patient 4, Table I).

in acute and chronic inflammatory liver disease, ${ }^{25} 34$ and we find similar expression in our patients with PSC and PBC. Although we did not detect any difference in endothelial staining by anti-E-selectin and anti-VCAM in patients compared with controls, we examined specimens with mainly portal tract changes, whereas increased expression of E-selectin and VCAM has been reported in parenchymal liver inflammation. ${ }^{34} \mathrm{We}$ were particularly interested to examine expression on biliary epithelial cells, as the finding of increased expression of MHC class II molecules by the biliary epithelium in PSC $^{8}$ suggests that biliary epithelial cells may participate in presenting antigen to $T$ cells. In addition, phenotypic analysis of $T$ cell subsets in the liver shows CD8 + cells around proliferating ductules and medium/large bile ducts. ${ }^{5}$ This does not prove that these cells mediate cytolytic activity; it is possible for instance that cytokines released in situ by activated CD8 + lymphocytes initiate or sustain destructive processes. Nevertheless, defining the co-stimulatory molecules participating in interaction between biliary epithelium and neighbouring lymphocytes at various stages of disease is of considerable interest.

Recent studies of cell adhesion molecules in PSC and PBC, 25-27 have reported conflicting results. Adams et al ${ }^{27}$ report a series of 13 patients with PBC and seven patients with PSC studied at liver transplantation and found that patients with end stage PSC and PBC expressed ICAM on interlobular bile ducts and proliferating bile ductules although larger bile ducts were negative. In contrast, Broome et $a l^{26}$ found ICAM on interlobular bile ducts of only one of 13 patients with PSC of varying histological grades and severity as assessed by Child-Pugh class, and on three of 10 patients

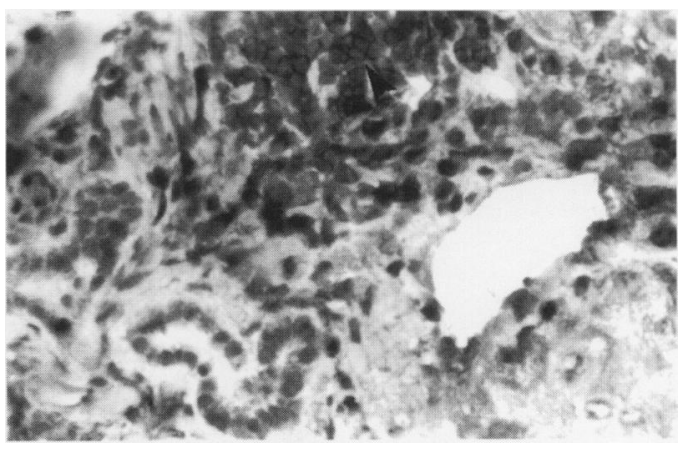

Figure 5: Infiltrating mononuclear cells (arrowed) staining with anti-LFA-1 in PSC (patient 14, Table I). 
with PBC despite almost $100 \%$ positivity for HLA-DR on biliary epithelium. If the high frequency of ICAM expression found on the biliary epithelium by Adams $e t$ al is a feature of end stage liver disease rather than PSC in itself, the discordance in these results might result from differences in severity of the liver disease in the two populations. In support of this, pre-cirrhotic PBC patients studied by Adams et al showed much weaker staining of biliary epithelium with anti-ICAM, with the amount of staining being correlated to the degree of inflammation.

Our principal result in this paper is that five of seven $(70 \%)$ of specimens from patients with histological stage 3 or 4 PSC express ICAM-1 on proliferating bile ductules and interlobular bile ducts, while of the patients with stage 1 or 2 disease none expressed ICAM-1 on bile ductules or small ducts. In PBC, however, we find ICAM to be expressed on bile ducts in two of seven cases of early disease (although larger - that is, septal/ trabecular ducts, were absent from four specimens) and in only one of five patients $(20 \%)$ with stage 3 or 4 disease. This difference in expression of ICAM-1 by biliary epithelium in histologically advanced PSC compared with PBC is surprising and suggests that there may be something specific about the mechanism of bile duct damage in PSC.

From published studies, it is uncertain whether ICAM expression on biliary epithelium is an early event in the development of disease or a secondary response to inflammation. We suggest that our finding of ICAM only in advanced PSC and expression of HLADR, which seems to predate expression of ICAM-1 on biliary epithelium makes a primary role for ICAM in bile duct damage less likely. HLA-DR was found to be expressed in most cases of large duct obstruction, which agrees with previous studies. ${ }^{8}$

The dissociation between HLA-DR and ICAM expression is interesting because both MHC class II molecules and pairs of 'costimulatory' molecules such as ICAM-1/LFA1 are required for presentation of exogenous antigen to a $\mathrm{T}$ cell. One possibility, which we have not investigated here, is that the variable expression of ICAM-1 is related to the cytokine profile in situ: it might be that HLADR expression is related to local interferon gamma, while ICAM-1 is related to interleukin 2 or tumour necrosis factor alpha concentrations. The fact that ICAM is not expressed on biliary epithelium early in the disease suggests that it does not participate in primary pathogenesis of biliary destruction. The presence of LFA-1 on infiltrating inflammatory cells raises the possibility that ligands for LFA-1 other than ICAM-1 may participate in antigen specific immune interactions. Alternatively, other ligand receptor pairs of adhesion molecules may be involved. Others have examined the distribution in hepatic inflammation of CD2 on infiltrating mononuclear cells and its ligand LFA-3 and have found that the staining pattern of LFA-3 closely mirrors that of ICAM-1, ${ }^{25}$ implying that this probably does not participate in mediating immune interactions with biliary epithelial cells.

It is interesting to compare these results with those found in inflammatory bowel disease, as although the expression of ICAM-1 is upregulated in the intestinal lamina propria in both ulcerative colitis and Crohn's disease, ICAM-1 has not been found on colonic epithelium ${ }^{35}$ despite expression of MHC class II antigens on intestinal epithelium in inflammation ${ }^{36}$ and other evidence suggesting a role for the colonic epithelial cell as an antigen presenting cell. ${ }^{37}$ This raises the possibility that other, as yet unidentified, accessory molecules may participate in mediating adhesion and cellular cytotoxicity between biliary epithelial cells and immune effector cells in inflammatory liver disease.

We are grateful to Andrew Heryet for his expertise in immunohistochemistry. SB is an MRC training fellow.

1 Wiesner R, LaRuso N, Ludwig J, Dickson E. Comparison of the clinicopathological features of primary sclerosing cholangitis and primary biliary cirrhosis. Gastroenterology 1985; 88: 108-14.

2 Schrumpf E, Fausa O, Forre O, Dobloug J, Ritland S, Thorsby E. HLA antigens and immunoregulatory T cells in ulcerative colitis associated with hepatobiliary disease. in ulcerative colitis associated with hepat
Scand $\mathcal{J}$ Gastroenterol 1982; 17: 187-91.

3 Chapman R, Varghese Z, Gaul R, Patel G, Kokinon N, Sherlock $S$. Association of primary sclerosing cholangitis with HLA-B8. Gut 1983; 24: 38-41.

4 Martins EB, Chapman RW, Fleming KA. $\gamma \delta \mathrm{T}$ cells in peripheral blood of patients with primary sclerosing cholangitis. Gut 1993; 34: A718.

5 Whiteside T, Lasky S, Si L, Van Thiel D. Immunologic analysis of mononuclear cells in liver tissues and blood of patients with primary sclerosing cholangitis. Hepatology 1985; 5: 468-74.

6 Sanchez-Tapias J, Thomas H, Sherlock S. Lymphocyte populations in liver biopsy specimens from patients with populations in liver biopsy specimens from patie

7 Lindor $\mathrm{K}$, Wiesner $\mathrm{R}$, LaRusso $\mathrm{N}$, Homberger $\mathrm{H}$ Enhanced autoreactivity of $T$ lymphocytes in primary sclerosing cholangitis. Hepatology 1987; 7: 884-8.

8 Chapman R, Kelly P, Heryet A, Jewell D, Fleming K. Expression of HLA DR antigens on bile duct epithelium in primary sclerosing cholangitis. Gut 1988; 29: 422-7.

9 Ballardini G, Bianchi F, Doniach D, Mirakian R, Pisi E, Bottazzo GF. Aberrant expression of HLA-DR antigens on bile duct epithelium in primary biliary cirrhosis: relevance to pathogenesis. Lancet 1984; ii: 1009-13.

10 Yamada G, Hyodo I, Tobe $K$, Mizuno $M$, Nishihara T, Kobayashi T, et al. Ultrastructural immunocytochemical analysis of lymphocytes infiltrating bile duct epithelia in analysis of lymphocytes infiltrating bile duct epithelia

11 Chapman R, Cottone M, Selby W, Shepherd H, Sherlock $S$, Jewell D. Serum autoantibodies, ulcerative colitis and primary sclerosing cholangitis. Gut 1986; 27: 86-91.

12 Snook JA, de Silva H, Jewell DP. The association of autoimmune disorders with inflammatory bowel disease. $Q \mathcal{F}$ Med 1989; 72: 835-40.

13 Springer $T$. Adhesion receptors of the immune system. Nature 1990; 346: 425-34.

14 Dustin M, Springer T. T cell receptor cross-linking transiently stimulates adhesiveness through LFA-1. Nature 1989; 341: 619-24.

15 Marlin S, Springer T. Purified intercellular adhesion molecule-1 (ICAM-1) is a ligand for lymphocyte function-associated molecule 1 (LFA-1). Cell 1987; 561: 813-9.

16 Staunton D, Dustin M, Springer T. Functional cloning of ICAM-2: a cell adhesion-ligand for LFA-1 homologous to ICAM-1. Nature 1989; 339: 61-4.

17 Fawcett J, Holness C, Needham L, Turley H, Gatter K, Mason D, et al. Molecular cloning of ICAM-3, a third ligand for LFA-1, constitutively expressed on resting leucocytes. Nature 1992; 360: 481-4.

18 Dustin M, Rothlein R, Bhan A, Dinarello C, Springer T. Induction by IL-1 and IFN-gamma: tissue distribution, biochemistry and function of a natural adherence molecule (ICAM-1). f Immunol 1986; 137: 245-54.

19 Broome U, Glauman $H$, Hultcrantz $R$, Forsum $U$. Distribution of HLA-DR, HLA-DP, HLA-DO antigens in liver tissue from patients with primary sclerosing in liver tissue from patients with primary scler

20 Spengler U, Pape G, Hoffman R, Johnson J, Eisenberg J, Paumgartner G, et al. Differential expression of MHC Paumgartner $\mathrm{G}$, et al. Differential expression of MHC class II subregion products on bile duct epithelial cells and
hepatocytes in patients with primary biliary cirhosis. hepatocytes in patients with

21 Lawrence $M$, Springer T. Leucocytes roll on a selectin at physiological flow rates: distinction from and prerequisite for adhesion through integrins. Cell 1991; 65: 859-73. 
22 Ley K, Gaehtgens P, Fennie C, Singer M, Lassky L, Rosen $S$. Lectin like cell adhesion molecule 1 mediates leucocyte rolling in mesenteric venules in vivo. Blood 1991; 77 2553-5

23 Hogg N. Roll, roll, roll your leucocyte gently down the vein. Immunol Today 1992; 13: 113-5.

24 Pardi R, Inverardi L, Bender J. Regulatory mechanisms in leucocyte adhesion; flexible receptors for sophisticated leucocyte adhesion; flexible receptors for
travellers. Immunol Today 1992; 13: 224-30.

25 Volpes R, van den Oord J, Desmet V. Immunohistochemical study of adhesion molecules in liver histochemical study of adhesion molecul

26 Broome U, Hultkrantz R, Scheynius A. Lack of concomitan expression of ICAM-1 and HLA-DR on bile duct cells from patients with primary sclerosing cholangitis and primary biliary cirrhosis. Scand 7 Gastroenterol 1993; 28: 126-30

27 Adams DH, Hubscher SG, Shaw J, Johnson GD, Babbs C Rothlein R, et al. Increased expression of ICAM 1 on bile ducts in primary biliary cirrhosis and primary sclerosing cholangitis. Hepatology 1991; 14: 426-31.

28 Chapman R, Arborgh B, Rhodes J, Summerfield JR, Scheuer P, Sherlock S. Primary sclerosing cholangitis: review of its clinical features, cholangiosing cholangitis: a review of its clinical features, ch.

29 Wiesner $R$, LaRusso $N$. Clinicopathologic features of the syndrome of primary sclerosing cholangitis Gastroenterology 1980; 79: 200-6.
30 Nakanuma Y, Ohta G. Histometric and serial section observations of the intrahepatic bile ducts in primary biliary cirrhosis. Gastroenterology 1979; 76: 1326-32.

31 Ludwig J, Dickson E, McDonald G. Staging of chronic nonsupportive destructive cholangitis syndrome of primary biliary cirrhosis. Virchows Arch Pathol Anat primary biliary cirrhosis. Virchous

32 Ludwig J, Barham SS, LaRusso NF, Elveback LR, Wiesner RH, McCall JT. Morphologic features of chronic hepatitis associated with primary sclerosing cholangitis hepatitis associated with primary sclerosing cholang

33 Hibbs M, Xu H, Stacker S, Springer T. Regulation of adhesion to ICAM-1 by the cytoplasmic domain of LFA1 Integrin b subunit. Science 1991; 251: 1611-3.

34 Volpes R, Van DOJ, Desmet VJ. Vascular adhesion molecules in acute and chronic liver inflammation. Hepatology 1992; 15: 269-75.

35 Malizia G, Calabrese A, Cottone $M$, Raimondo $M$, Trejdosiewicz LK, Smart CJ, et al. Expression of leukocyte adhesion molecules by mucosal mononuclear phagocytes in inflammatory bowel disease. Gastroenterology cytes in inflammat 100 : 150-9.

36 Selby WS, Janossy G, Mason DY, Jewell DP. Expression of HLA-DR antigens by colonic epithelium in inflammatory bowel disease. Clin Exp Immunol 1983; 53: 614-8.

37 Mayer L, Shlien R. Evidence for function of Ia molecules on gut epithelial cells in man. $\mathcal{F} \operatorname{Exp}$ Med 1987; 166: 1471-83. 